TO APPEAR IN OXFORD HANDBOOK OF PHILOSOPHY OF PSYCHIATRY. PLEASE REFER TO PUBLISHED VERSION IF QUOTING.

\title{
Psychopathology and the Enactive Mind
}

\author{
Giovanna Colombetti \\ Department of Sociology and Philosophy \\ University of Exeter
}

\begin{abstract}
According to the 'enactive' approach in philosophy of mind and cognitive science, mental states are neither identical with, nor reducible to, brain activity. Rather, the mind is enacted or brought forth by the whole situated living organism in virtue of its specific structure and organization. Although increasingly influential in cognitive science, the enactive approach has had little to do with psychopathology so far. In this chapter I thus first outline this approach in some detail, and then illustrate its conceptual and methodological connections to psychopathology. I also provide some indications on how to develop a more explicitly 'enactive psychopathology'.
\end{abstract}

Keywords: enaction, embodiment, phenomenology, psychopathology 


\section{Psychopathology and the Enactive Mind}

\section{The enactive approach}

The term 'enaction' was originally introduced in philosophy of mind and cognitive science by Varela et al.'s The Embodied Mind to characterize a conception of mind and cognition profoundly different from the computational-representational one of mainstream cognitivism:

'We propose ... the term enactive to emphasize the growing conviction that cognition is not the representation of a pregiven world by a pregiven mind but is rather the enactment of a world and a mind on the basis of a history of the variety of actions that a being in the world performs'. (Varela et al. 1991, p.9)

The terms 'history', 'actions', 'world' and 'perform' underscore main features of the enactive mind, namely its dynamical, embodied and situated character. Cognition is not 'inside' the brain, representing information about the world, computing it according to internal rules, and eventually telling the body how to act; cognition is rather enacted or brought forth, over time, by the whole organism (not just its brain) situated in the world.

This view was not new, and Varela and colleagues indeed explicitly presented their work as a continuation of Merleau-Ponty's Structure of Behaviour (1942/1963) and Phenomenology of Perception (1945/1962). Merleau-Ponty had already defended the thesis of the thoroughly embodied and situated nature of the mind on the basis of phenomenological and empirical considerations, and had himself been influenced by Husserl and Gestalt psychologists (just to mention his most proximate sources). Varela et al. importantly brought these ideas into Anglo-American cognitive science, joining the efforts of authors such as Dreyfus (1972), who had already drawn on continental philosophy to criticize the possibility of symbolic artificial intelligence.

Since the publication of The Embodied Mind, the embodied, situated and active character of cognition has been emphasized in particular by defenders of the 
view that perception and action are intimately tied together, indeed that they are mutually constitutive rather than mediated by an internal representational system (Hurley 1998; O’Regan and Noë 2001; Noë 2004). At the same time, supporters of the dynamical systems approach in cognitive science (Thelen and Smith 1994; Port and van Gelder 1995; Kelso 1995; Thelen et al. 2001) and situated robotics (Brooks 1991; Matarić 2002) have also underscored the temporal, embodied and highly context-dependent character of various cognitive and motor abilities, fuelling the philosophical debate on the mind-body relationship and, more specifically, on the representational nature of the mind (cf. Clark 1997; Wheeler 2005).

It would be restrictive however to reduce the enactive approach to the view that cognition, and perception in particular, is active, embodied and situated. Enactivism is a complex approach to the conceptualization and study of the mind that draws also on, for example, large-scale accounts of brain activity, philosophical and biological theories on the nature of living systems, the relationship of life to mind, and the nature of consciousness. All these threads have been woven together by Thompson (2007) in what can be considered the ultimate synthesis of the enactive approach, and more are already being spun (see the recent collection by Stewart et al. 2010).

For present purposes, I will pull out only those threads that are relevant to the main goal of this chapter, which is to illustrate points of convergence between enactivism and psychopathology, and to suggest possible ways to integrate them more explicitly. The threads I have chosen are the following:

(1) Enactivism's insistence on the importance of developing rigorous first-person methods for the study of consciousness, and for the 'neurophenomenological' integration of first- and third-person data, namely data about lived experience and data about physiological activity.

(2) Enactivism's emphasis on the affective nature of cognition.

(3) Enactivism's emphasis on the direct bodily and affective nature of intersubjectivity.

Let us now take a closer look at each of these points.

\subsection{Neurophenomenology}


Varela et al. (1991) already argued that cognitive science, in order to be a science of the mind, ought to pay serious attention to the study of consciousness. In particular, they emphasized the need to have a well-developed first-person method for such a study, which led them to discuss the very old and established Buddhist discipline of 'mindfulness meditation'. The latter consists in the cultivation of self-awareness by way of practices aimed at making one increasingly 'present' to one's own mind, namely increasingly awake to the contents of one's own consciousness and to the 'habits' of one's own mind.

This emphasis on the need for a systematic and disciplined observation of lived experience subsequently led Varela (1996) to elaborate his specific proposal for a neurophenomenological method that could integrate data about experience (firstperson data) and data about brain activity (third-person data). According to Varela, the former are necessary to make sense of the latter; vice-versa, the latter should be used to refine the former. From a philosophical standpoint, neurophenomenology can be seen as a method for 'naturalizing phenomenology', that is, for making experience amenable to natural scientific enquiry. Importantly neurophenomenology does not call for the reduction of the experiential level to the physiological one; it does not attempt, for example, to translate first-person data into third-person ones (for this approach, see Roy et al. 1999). Quite the opposite, it calls for the inclusion of first-person data as such in the natural-scientific enterprise of understanding how the organism enacts consciousness.

A few experiments have now been conducted under the neurophenomenological agenda. ${ }^{1}$ In a much-cited study, Lutz et al. (2002) trained subjects to report precisely on their experience of coming to see a three dimensional image from a 'magic eye picture' (a two-dimensional random dot pattern with binocular disparities). This training allowed both subjects and experimenters to identify categories of experience (feeling 'ready' to see the image, feeling completely 'unready', and feeling in a middle state of 'fragmented readiness') that were subsequently used to make sense of patterns of brain activity recorded while subjects looked at the dot patterns. Lutz et al. (2002) indeed were able to identify distinctive

\footnotetext{
${ }^{1}$ For a comprehensive discussion of the neurophenomenological approach, including a summary of relevant experimental work, see Thompson et al. (2005).
} 
patterns of EEG activity corresponding to the experiential states of readiness, unreadiness, and fragmented readiness respectively.

The fact that subjects were trained to observe and report on their experience is particularly significant, and characterizes this study as neuro-phenomenological. Importantly, training occurred via a mixture of 'first-person' and 'second-person' methods, namely via self-observation but also in interaction with an interviewer, whose role was to guide subjects to pay attention to different aspects of their experience. Furthermore, the interviewer asked 'open questions' that did not constrain the range of answers the subjects could give.

It may be objected that there is nothing special or different about neurophenomenology compared to the more familiar cognitive-neuroscientific approach. After all, neurophenomenologists also appear to be looking for the neural correlates of consciousness; moreover, neurophenomenology is entirely brain-oriented and as such appears to be at odds with Varela's own embodied-enactive predicaments. There are however at least two important differences between neurophenomenology and cognitive neuroscience. First, neurophenomenology believes that it is not only possible but necessary to develop first-person method to obtain reliable first-person data. Cognitive neuroscience on its part tries to minimize reliance on self-reports, which it generally sees as biased and untrustworthy, and takes behaviour to be a more objective measure of cognitive activity. Whereas neurophenomenologists collect firstperson data at the beginning of a study and use them as an 'organizing analytical principle' (Gallagher 2003, p.86), cognitive neuroscientists collect self-reports, if at all, only at the end of a study and mainly for control purposes. Second, neurophenomenology does not regard brain activity as sufficient for experience; it regards it as just one part of the broader organismic processes that underpin, or better enact, consciousness. $^{2}$

Admittedly only a few neurophenomenological studies have been conducted so far, and the extent to which it is possible to map the structure and dynamics of lived experience onto the one of neural and perhaps even non-neural bodily activity remains an open question. For present purposes however, what matters is the shift of

\footnotetext{
${ }^{2}$ See Colombetti (in preparation) for a less brain-centered 'neuro-physiophenomenology' that aims at integrating data about experience with data about brain and non-neural bodily processes.
} 
attitude towards lived experience that is entailed by neurophenomenology compared to mainstream cognitive neuroscience, in particular the idea that the neuroscientific study of consciousness must include asking subjects what they feel without constraining their answers, and using their answers to shed light on the structure of specific experiences as well as the physiological activity supposedly enacting them.

\subsection{Sense-making and the affective nature of cognition}

In the enactive approach, cognition and affectivity are not regarded as two distinct psychological faculties. Rather, cognition is inherently affective. To see how, we need to look briefly at the notion of sense-making as it appears in Varela's later writings and subsequent elaborations of the enactive approach. This in turn requires a detour into the enactive conception of life and of its relationship to cognition. The whole story is quite complex and difficult to recount without introducing technicalities, but for present purposes it will suffice just to highlight some of its main points (for the details, see Thompson 2007, especially chapters 3, 5 and 6).

At the very roots of the enactive approach is the claim that all living systems are cognitive systems (Maturana and Varela 1980). Specifically, they are cognitive in virtue of their autonomous and adaptive nature. An autonomous system is defined as one whose constituent processes "(i) recursively depend on each other for their generation and their realization as a network, (ii) constitute the system as a unity in whatever domain they exist, and (iii) determine a domain of possible interactions with the environment" (Thompson 2007: 44). The paradigmatic autonomous system is the living cell. Multicellular metazoan systems, nervous systems, insect colonies etc. however are also autonomous, even if they do not have a material boundary; they are all importantly 'operationally closed' systems, constituted by processes whose results remain within the system itself. Adaptivity on its part refers to the capacity of living systems to monitor and regulate themselves with respect to their conditions of viability, and to improve their situation when needed (Di Paolo 2005).

According to the enactive approach, the autonomous and adaptive nature of living systems makes them into sense-making systems, that is, systems that have a perspective or point of view from which they establish their own world of meaning- 
their Umwelt, to use Von Uexküll's (1921) term. ${ }^{3}$ As Weber and Varela (2002, pp.117-118) succinctly put it: '[b]y defining itself and thereby creating the domains of self and world, the organism creates a perspective which changes the world from a neutral place to an Umwelt that always means something in relation to the organism'. The Umwelt is thus not a world 'outside' the living system in which the latter grows and moves, and into which it occasionally bumps; rather the living system enacts or performs its Umwelt, very much like one 'lays down a path in walking' (to use Varela's analogy). Importantly, according to the enactive approach, the process of establishing a world of significance in this way is the basic 'mark of the cognitive'.

This characterization of cognition entails affectivity, in the broad sense that the living organism is never indifferent to its existence and environment. As Weber and Varela (2002) remark in several passages, the perspective or point of view of the sense-making living system is concerned; the living system 'is interested' and 'cares' about its own continuation, so to speak. ${ }^{4}$ This concern is the correlate of another important property of living systems, namely their inherent purposefulness: the constituent processes of a living system conspire to maintain its identity against a variety of perturbations; in other words the living system strives, as a function of its organization, to maintain itself and its conditions of viability. Finally, the very notion of an Umwelt is also affective in a broad sense: the Umwelt, as enacted by the organism, represents what is relevant or salient for the organism, what matters to it. ${ }^{5}$

From an enactive perspective then, it is not really possible to distinguish cognition from affectivity without providing a somewhat distorted notion of cognition. The separation of cognition and affectivity is an abstraction, the imposition of a distinction onto what is fundamentally a simultaneously cognitive-affective phenomenon.

\footnotetext{
3 'Umwelt' literally means 'world around' and is usually translated as 'environment'. The German term however is used here to refer specifically to the environment from the perspective of the living system.

${ }^{4}$ Weber and Varela (2002) draw largely on Jonas (1966/2001). See Thompson (2007) for a more detailed account of the relationship between enactivism and Jonas's conception of life.

${ }^{5}$ For a more detailed discussion of the affective nature of sense-making, see Colombetti (in preparation).
} 
A critical aspect of this view is that it is the whole organism, not just the brain, that makes sense of the world. This approach differs considerably from the one of mainstream affective science, according to which the faculty responsible for evaluating the world in relation to the subject's needs and concerns, the 'appraisal', is typically characterized as a 'non-bodily' cognitive process. The widespread assumption is that the appraisal is a cognitive process realized by some part of the brain, which evaluates various aspects of a situation and brings about a series of responses in body, behaviour, feeling, etc. ${ }^{6}$ Even when the cognitive appraisal is viewed as a component of emotion (e.g. Scherer 2009), it is still conceptualized as an intellectual brainy event distinct from the rest of the organism. From an enactive perspective, on the other hand, the process of evaluating the world in relation to one's needs and concerns is enacted by the whole organism in virtue of its organization (for arguments, see Colombetti 2007, 2010; Colombetti and Thompson 2008).

\subsection{Participatory sense-making}

Another recent thread developed within the enactive approach regards the social dimension of cognition. In this context, De Jaegher and Di Paolo (2007) have proposed the notion of participatory sense-making, which extends the enactive notion of sense-making introduced above to the domain of 'being together'. They particularly emphasize that accounts of social cognition should not overlook the concrete face-to-face (or rather, we should say, body-to-body) interactions that pervade our daily living together, namely what Trevarthen (1979) originally dubbed 'primary intersubjectivity, i.e. a set of embodied and affective skills involved in nonconceptual and pragmatic understanding of others. These interactions, they point out, typically enact or bring forth a specific form of shared meaning that cannot be reduced to each participant's own sense-making. The interaction, we can say, imposes a kind of second-order constraint over the participants, and develops a 'life of its own' characterized by its own specific style of unfolding; in other words, the interaction develops its own form of autonomy. De Jaegher and Di Paolo (2007) particularly emphasize the character of 'coordination' of concrete social encounters, namely the

\footnotetext{
${ }^{6}$ Details vary from one theory of appraisal to the other (see Scherer et al. 2001 for an overview of the field).
} 
sustained, non-accidental coupling between participants. The notion of coupling at play here is borrowed from dynamical systems theory; in simple terms, it refers to a process of continuous reciprocal influences between systems (organisms included), such that they can be considered one single system. The classic example is the one of two pendulums hanging from the same wall that end up oscillating at the same frequency (in virtue of the vibrations that each pendulum transmits to the wall), but the phenomenon is widespread in physical and biological systems.

We know that human intersubjectivity in particular is characterized by phenomena of spontaneous mimicking, mirroring and affect attunement. The perception of facial expressions of emotions induce in the perceiver distinct facial reactions that mimic at least parts of the perceived expression (e.g. Dimberg et al. 2000). Neural mirror systems exist for both perception and emotion expression. The perception of another's specific goal-oriented action activates one's own neural motor system for that action; the perception of another's expression of disgust activates neural areas that are also active when one experiences disgust oneself (see Rizzolatti and Sinigaglia 2006/2008 for an overview of the relevant findings). Furthermore, caregivers 'attune themselves' to children by reproducing cross-modally the dynamic features of their affective states, such as intensity, timing and shape (Stern 1985).

The enactive approach emphasizes that these modes of bodily and affective coupling are pervasive and continuous with 'higher order' phenomena of social cognition, such as cognitive empathy and enculturation (both discussed in Thompson 2007, chapter 13; see also Gallagher 2001). Even if during one's lifetime one will develop different modes of interacting with others, bodily and affective coupling is not transcended as the organism grows older. Other organisms are part of the environment in which we are situated, and interactions with them are a constitutive part of the process of enacting a world of significance.

Also, unlike mainstream positions in the so-called Theory of Mind debate, the enactive approach emphasizes the immediate and direct 'understanding of the other' that characterizes concrete encounters. The idea is that in order to understand the other's actions or expressions, we need neither to recur to a 'theory' (as in the socalled 'theory theory'), nor to 'simulate' the other's state in ourselves (as posited by the 'simulation theory'). We do not infer the other's intentions and emotions via some intermediate mental operation, but we 'directly' see the other's mind in her bodily attitude. Again, this point is borrowed from phenomenology, specifically from 
accounts of intersubjectivity and empathy developed by Stein, Scheler, and others (for references and discussion, see e.g. Zahavi 2007).

\section{Connections with psychopathology}

Enactivist ideas so far have not been applied to develop worked-out theories and methods in psychopathology (for some initial discussions, see Fuchs 2009 and Drayson 2009). There are however various points of contact between enactivism and current trends in psychopathology—most notably in phenomenological psychopathology. The latter emphasizes that lived experience ought to be taken seriously, without reducing it to neural activity and/or behaviour. Phenomenological accounts of mental illness also underscore its bodily and situated character, as well as the profound transformations in the sense of reality and 'being there' that it involves. The cognition-affect dichotomy has also begun to falter under these more existential accounts of mental disorders that emphasize changes in 'feelings of being', rather than (or at least in addition to) 'false beliefs'. The enactive approach sits well also with pluralistic approaches to treatment which employ bodily practices to modify the organism's dynamics and its modes of relating to the world, including other people. I will now look at these points of contact in more detail and, when appropriate, develop them further into suggestions on how to elaborate a more explicitly 'enactive psychopathology'.

\subsection{Towards a 'neurophenomenological psychopathology'}

We have seen that phenomenology, understood as the systematic analysis of the structures of experience, is central to the enactive approach; it is necessary for the scientific study of the mind, and in particular for progressing our understanding of how consciousness and physical processes are related. Not only is lived experience a fundamental aspect of mentality, but in order to study it, it is necessary to describe and analyse it as accurately as possible, and to develop appropriate tools and methods for this purpose.

Phenomenology as a descriptive and analytical tool has also been advocated in psychopathology since Jaspers (1913/1997). Jaspers advocated phenomenology as a method for providing concrete descriptions of patients' mental states, for analysing 
their interrelations, and for identifying, differentiating and labelling them appropriately. He particularly valued patients' self-observation as a primary source of data, and open-mindedness on the part of the psychopathologist. The latter should neither be too impressed by specific claims on the part of the patient, nor restricted by theoretical presuppositions. Individual cases should be carefully scrutinized, with the aim of recognizing recurrent similar patterns within and across patients. ${ }^{7}$

Since Jaspers, phenomenology has made its way into psychopathology in a variety of ways, with the works of Binswanger, Minkowski, Straus, Buytendijk, and others (see Spiegelberg 1972 for a historical overview). Recent arguments for a role of the phenomenological method in psychopathology, and specific examples of the application of phenomenological categories to the understanding of mental disorders, can be found for instance in Sass (1992), Parnas and Zahavi (2002), Stanghellini (2004), Gallagher (2005), Fuchs (2005), Mullen (2007) Ratcliffe (2008) and Sass et al. (2011) (the list is not exhaustive). These works all resist and oppose the widespread reductionist attitude of much current psychiatry, which is interested in patients' lived experience primarily for the purpose of merely 'spotting' symptoms already provided by the diagnostic manuals; once key symptoms are identified, experience is quickly left aside to examine 'more objective' behavioural and neural data, and to identify appropriate pharmacological treatments.

This method is particularly limiting given that the diagnostic manuals provide very succinct snapshots of experience, intentionally leaving aside alleged irrelevant and distracting details. The result is a rather mechanical process in which there is little room for the identification of features of experience that have not been previously recognized as symptomatic. As Mullen (2007, p.114) complains, '[w]e now have generations of mental health professionals, many of whom have learned all the right questions. They may in the process, however, have lost the capacity to listen or to see what may challenge or otherwise discomfort the established diagnostic process'.

\footnotetext{
${ }^{7}$ Jaspers' phenomenological approach departs in various respects from Husserl's, in particular from the latter's quest for 'essences', and more could be said about the relation between these two approaches. For the purposes of this chapter however I simply intend to point out the importance that both enactivists and some philosophers and psychiatrists grant to the development of methods for the exploration of consciousness.
} 
By contrast, phenomenological psychopathology takes lived experience to be an essential aspect of mental illness that deserves full attention and that ought to be examined in detail. It uses existing phenomenological concepts and analyses (e.g. of self-awareness, temporal experience, background attunements), or develops new ones, in order to provide detailed and precise accounts of the experience of a variety of mental disorders. The results often challenge received views. Ratcliffe (2008), for example, uses his category of existential feeling to criticize accounts of delusions that only emphasize distortions of 'beliefs'. According to Ratcliffe, delusions involve fundamental changes in 'how one finds oneself in the world' in terms of existential background orientations - as when we say that one feels 'at home in the world', or alone, estranged, connected, in tune, etc. These ways of feeling are not directed at specific objects or events, but are backdrop orientations against which other experiences take place, and which also determine the kind of experiences one has or is likely to have. Like Heidegger's (1927/1962) moods, Ratcliffe's existential feelings are not merely contingent colorations of consciousness, but fundamental ways of being attuned to the world. They cannot be reduced to propositional attitudes, i.e. mental states such as beliefs that take propositions as objects ('I believe that this body is not mine', 'I believe that someone is putting thoughts in my head'). Hence disorders such as Capgras' delusion for example, where subjects report believing that other people (usually relevant others such as partners, relatives or close friends) are in fact impostors pretending to be them, cannot be reduced to mere false beliefs but encompass a deeper change in existential feeling, namely in how reality as a whole and oneself in it are experienced.

Valuing lived experience in psychopathology is not just an exercise in phenomenological analysis per se, but has relevant diagnostic and therapeutic implications. Classifications of mental disorders are notoriously fuzzy and fluid. More dramatically, they are, as Hacking (e.g. 1999, p.103) puts it, interactive kinds, they 'can influence what is classified' and can be modified or replaced because they interact with what is classified. Interactive kinds induce 'classificatory looping effects': the thing classified changes its behaviour as a consequence of being so classified, which in turn requires a change in the original classification, and so on. These looping effects, as Hacking (1999) illustrates, are revealed in the history of the classification of psychopathologies such as mental retardation, childhood autism, and schizophrenia, as well as multiple personality disorder (Hacking 1995), and the now 
extinguished fugue (Hacking 1998). This history shows that psychopathologies are 'moving targets' - their descriptions and classifications vary over time, and with them the behaviour and experience of the people classified, which in turn induces new descriptions and classifications, etc. Hence both the way a mental disorder manifests itself in behaviour and experience, and the diagnostic categories used to identify it, are subject to fluctuations and variations; looking up a pre-given fixed list of symptoms may thus become inadequate, or even a hindrance, to a comprehensive understanding of a specific condition.

The phenomenological approach in psychopathology is better suited than mainstream psychiatry to track these looping effects, because it aims to engage repeatedly with the patient to identify salient features of his life and experience, and to do so without imposing theoretical pre-conceptions and schemata. Mullen (2007, pp.117-118) lists five stages that, in his view, ought to characterize a thoroughly phenomenological method in psychopathology. The first consists in facilitating spontaneous accounts of experience and behaviour, without being guided by assumptions about what counts as pathological, reasonable, symptomatic, plausible, etc. A structured investigation may also be used that focuses on experiential categories such as experience of time, distance, direction, reality, causation, sense of control and agency, etc. This process should be repeated in the course of therapy, not just confined to preliminary stages. The second stage consists in 'augmenting' selfaccounts with artistic, literary and philosophical works that also provide descriptions and analyses of experience with which the patient resonates. Third, the therapist should be empathetic and try to grasp the qualities of the patient's lived experience, as well as help him or her find words for it. This use of empathy should remain modest, and avoid imposition of pre-established theoretical frameworks and evaluations. In the fourth stage a summative description of the patient's experience and behaviour is derived. Some ordering and systematization is applied at this point. In the final stage phenomenological categories are brought in to produce a provisional classification which may be modified after subsequent observation of experience and behaviour.

This approach has a lot in common with neurophenomenology. Both methods reject a merely behaviouristic and/or neurophysiological stance; they take lived experience seriously and do not attempt to reduce it to something else. Both methods strive to minimize theoretical preconceptions about the nature of experience; they encourage spontaneous reports, as well as an empathetic relationship between 
therapist and patient (or experimenter/interviewer and subject) to provide rich descriptions of lived experience and to reveal structures and invariants that might otherwise remain unnoticed, or that are not part of standard descriptions of symptoms. Also, importantly, both approaches share a conception of experience that is far from fixed or static, but rather moving, fluctuating and developing, subject to endogenous (neural, biological) as well as contextual (immediate environment, other people, near past or future events) and broader social-symbolic influences. In neurophenomenology, as we have seen, this conception of experience as dynamical and open implies that first-person data can, and should, be changed and stabilized with first- and second-person methods, as well as refined by third-person data. In phenomenological psychopathology, the same conception implies that a subject's experience needs to be repeatedly engaged with and explored in the therapeutic context, rather than limiting this investigation to the initial stages of the diagnosis. Neither approach assumes that no invariant whatsoever can be identified in experience; rather, both imply that part of the process of understanding lived experience involves exploring its flexibility and openness, and the way it responds to intervention.

Now, phenomenological psychopathology and neurophenomenology so far have been separate fields of inquiry, but it is possible to envisage a 'neurophenomenological psychopathology' that extends the neurophenomenological method to the study of mental disorders. Such an approach would provide a bridge between biological and phenomenological strands within psychiatry, often considered incommensurable paradigms. Within such an integrated approach, lived experience would be explored systematically to identify relevant categories; the latter would then be used to organize and interpret data about neurophysiological activity; these data in turn could be used to identify finer-grained dimensions of experience. ${ }^{8}$

\footnotetext{
${ }^{8}$ One may note here that not all aspects of lived experience can be usefully linked to neurophysiological activity, and vice-versa; there may be features of the structure of experience that are not amenable to being illuminated by third-person data. Take for example the notion of the 'depth' of affective experience discussed by Ratcliffe (2010), which refers to the degree of specificity of the intentional object of an experience. On this account, the sadness for, say, the loss of one's favourite teddy bear is shallower than the sadness for one's inability to engage less than superficially
} 
Gallagher's (2005) account of schizophrenia can be seen as a step in this direction. He draws on Husserl's analysis of time-consciousness to provide a phenomenological account of experiences of thought insertion and loss of sense of agency typical of the condition. In particular, he argues that schizophrenia may involve a disruption in the protentional dimension of time-consciousness, namely in the orientation towards what-is-to-come-next that, according to Husserl, characterizes all experiences of the present moment. According to Gallagher, ordinarily our sense of agency - the pre-reflective sense that I am the one generating my thoughts and actions - is always protentionally oriented toward what is to happen next. If that weren't the case, I would be constantly surprised by my thoughts and actions, as if they had just appeared, unexpectedly, in my experience and behaviour; I would still have a sense of them as $m y$ thoughts and actions (sense of ownership would be retained), as in the case of ordinary unbidden memories, but I would not experience them as part of my agency. Gallagher proposes that this is just what happens in schizophrenia: the 'protentional mechanism' is disrupted, and with it the sense that one is the intentional future-oriented source of one's thoughts and actions. The latter thus appear 'inserted' by an outside source or force.

What makes Gallagher's discussion a step towards a neurophenomenological psychopathology is that he also compares his account with evidence from neuroscience, in particular with a study by Frith and Done (1988) showing that for 80 per cent of schizophrenic subjects with positive symptoms, the EEG response to tones generated by the subjects themselves by pressing a button was similar in amplitude to the response generated to randomly occurring tones. Previous evidence had shown that in non-schizophrenic subjects, random tones generate a relatively larger response than self-generated ones. Gallagher thus suggests that Frith and Done's result

with other people, which is in turn shallower than the sadness for the status of human rights in the world. These forms of sadness differ in existential import, and I agree that finding out that they corresponded to, say, different degrees of neural synchrony, would not be particularly interesting from a phenomenological-existential point of view. From the perspective of someone who is interested in how experience and physical processes are linked, however, it would be interesting to find out that the degree of specificity of the intentional object of an emotion corresponded reliably to different patterns of brain activity. 
confirms the view that schizophrenics fail to experience their own actions as selfgenerated, and rather experience them as surprising, as if they were generated from an outside source. These considerations could be used to design a neurophenomenological study that recorded neural activity as subjects reported their experiences 'online', to see whether specific experiences of loss of sense of agency are indeed correlated with distinctive patterns of neural activity.

Another relevant approach here is Petitmengin et al.'s (2006) work on epilepsy. They employed a phenomenological method to explore in detail the nature of preictical symptoms (the experiences that usually precede an epileptic seizure). Specifically, they were able to distinguish between the experiences occurring during the 'aura' (also known as simple partial seizure), which is sudden and relatively brief (it lasts a few seconds or minutes), and the 'prodromes', which are more progressive and can last up to a day. Unlike the aura, the prodromes have not been much investigated, and are not usually recognized and discussed in the clinical context.

The methodology that Petitmengin and colleagues employed to identify these differences in experience corresponds in many respects to the one recommended by Mullen (2007). They used a log form to ask hospitalized epileptic patients to reflect every morning on their state of fatigue, stress and emotional condition in general, as well as on particular bodily, visual and auditory sensations. Another log form with similar questions had to be filled in by the patients after each seizure; this form also asked patients to focus on the quality of their experience immediately before the seizure, to remember what they were doing then, at which moment they had started to feel specific sensations, how long did they last, and more. Similar questions were asked in another log form that patients had to fill after a 'mini-crisis', namely a preictal episode that did not lead to a full seizure. These forms importantly alternated questionnaires in which subjects had to rate their current condition on a numerical scale, with more open questions in which subjects were asked to report and describe it in their own words.

Semi-structured interviews were also used. In the first stage of the interview, patients were asked to recall a specific preictal experience, and to relive it by remembering in as much detail as possible the images, sensations, sounds, etc. associated with it. In the second stage, patients were asked to 'slow down' the recollection of their experience, to attend to, thematize or make explicit aspects of it that had so far remained implicit or unnoticed. In the third stage, the interviewer 
helped the patients put their experience into words. At the end of the process the investigators extracted the 'microstructure' of each personal experience (the precise sequence of sensations, feelings, etc. that constitute it) and detected regularities across experiences.

From a clinical perspective, this phenomenological work is in itself already very valuable. Epileptic patients are often only vaguely aware of how their experience changes in the hours preceding a seizure, yet they can learn to become more sensitive to these changes. This ability is particularly important for therapeutic purposes, because once subjects are able to 'catch' preictal symptoms in time, they can also learn to engage in activities that delay or even prevent the onset of a seizure.

Petitmengin and colleagues' approach however is not 'only' phenomenological but, like Gallagher's account of schizophrenia, attempts to bridge data about experience with data about neural activity. They compared the results of their phenomenological analysis with those of EEG measurements of the neural concomitants of preictal and ictal episodes. It had already been shown (e.g. Le Van Quyen et al. 2003) that about five minutes before the onset of a seizure, a decrease in synchronization or 'phase-scattering' characterizes brain activity around the epileptogenic focus; these brain areas also tend to become relatively isolated compared to the interconnectivity characterizing the interictal phase (the phase between seizures free from ictal and preictal symptoms). Petitmengin et al. (2007) suggest that these phase-scattering may be characteristic of prodromes, as opposed to the neural synchrony that characterizes the ictal phase (including the aura). This suggestion, as they acknowledge, still has to be verified as no study has been conducted yet on the 'real time' correlation between the microdynamics of experience and those of brain activity. Such a study would count as thoroughly neurophenomenological.

In addition, a thoroughly neurophenomenological study of epilepsy could use data about neural activity to refine first-person data. Specifically EEG data could be used as biofeedback to help epileptic subjects become more sensitive to changes in their experience. Biofeedback as a technique involves continuously measuring some dimension of a subject's biological activity, and showing the measurement to the subject in real time, as it is taking place. In biofeedback therapy, subjects use the real time signal to monitor and regulate their awareness. Attempts to use EEG biofeedback to treat epilepsy go back to the 1970s (see e.g. Cott et al. 1979); other dimensions of 
bodily feedback have been used since then to treat various conditions, such as migraine, muscle contraction, rheumatoid arthritis, and anxiety, including cardiophobia (Birbaumer and Kimmell 1979). Recent studies have shown that it is relatively easy to train subjects to regulate their emotion experience by using 'realtime fMRI' (deCharms 2008). Johnston et al. (2010) targeted brain areas known to activate significantly during unpleasant emotions, and showed subjects various positive, neutral, and negative pictures (that is, pictures known to elicit pleasant, indifferent, and unpleasant emotion experiences respectively). Subjects received feedback about activity in these areas by looking at the picture of a thermometer whose temperature reflected increases in fMRI amplitude signal, and were instructed to regulate activity in the target brain regions by relying on the feedback.

Interestingly, subjects were able to regulate activity in the target areas already from the first run.

Some mental disorders, starting with affective disorders, could be similarly approached by a neuroimaging-enhanced phenomenological method: subjects could become increasingly sensitive to changes in their awareness (like unpleasant or aversive feelings in response to specific stimuli that may initiate, for example, obsessive rumination) via the integrated use of self-exploration, second-person methods and biofeedback, and eventually learn to divert or even prevent unwholesome experiences. It is notable that recent approaches to depression have started to integrate cognitive behavioural therapy, which is based on the analysis of thoughts and behaviour, with 'mindfulness' therapy (derived from Buddhist mindfulness practices) that requires clients to cultivate a heightened awareness of their experience, not only of recurrent patterns of thoughts, but also of a variety of bodily sensations and feelings (see Segal et al. 2001). This approach could be used to explore specific features or forms of the experience of depression, inform findings about neurophysiological (neural, but also bodily) processes, and also use the latter to refine understanding of the experience of depression.

To recapitulate, in this section I have illustrated one line of convergence between the enactive approach and psychopathology, notably the primacy that both neurophenomenology (which is an offshoot of the enactive approach) and phenomenological psychopathology attribute to lived experience and to the development of rigorous methods for its investigation. In addition, I have suggested that the neurophenomenological method may be fruitfully applied to the study of 
mental disorders to provide a bridge between the more mainstream biological approach in psychiatry, and phenomenological psychopathology.

\subsection{Mental disorders as disorders of embodiment and situatedness}

In spite of neurophenomenology's focus on the brain, as we have seen the enactive approach rejects the view that the mind is in the brain. Rather, it maintains that mind and experience are enacted or brought fourth by the whole organism embedded in its environment. Analogous views can be found in psychopathology (and, again, especially in phenomenological psychopathology), in accounts of mental illness that emphasize its embodied and situated character versus the tendency to see it merely or primarily as a disorder of the brain. According to Fuchs (2009), for example, mental illness needs to be understood in the broader context of the embodied and situated nature of the person, namely as a disorder that straddles brain, body and world. As he points out, even when it is possible to identify neural impairments accompanying specific mental disorders, the neurobiological characterization of the disorder does not do justice to the patient's condition. Of course this claim does not entail that neurochemical imbalances do not contribute to disorders of experience and behaviour, or that a neurophenomenological approach could not reveal important neural characteristics of such disorders. The point is rather that the causal factors relevant to mental disorders extend well beyond the skull, and consist of a broader complex system of reciprocal influences crisscrossing brain, body and world.

Fuchs himself suggests to look at schizophrenia 'as a circular process, implying neuropsychological and biochemical dysfunction on the one hand and psychosocial alienation on the other' (Fuchs 2009, p.230). In his account, biological imbalances contribute to withdrawal from the world in the prodromal phases of the condition; withdrawal subsequently leads to disruption of attunement to the world and other people, which feeds back onto the subject's condition and eventually leads to psychotic crises and appearance of delusions. Similar considerations apply to depression, which according to Fuchs $(2001,2009)$ consists in a complete breakdown of the continuous engagement and 'synchronization' (his term) that characterize our everyday interactions with one another, as well as our relation to the environment more broadly. This breakdown results from an initial failure to cope with a major change, namely from a failure to re-synchronize with an altered world. The individual 
then retreats from the world by reducing her interactions with it, including other people. Social desynchronization eventually leads to 'biological desynchronization', manifested physiologically in disturbances of neuroendocrine processes, temperature, sleep-wake and menstrual cycles among other things. These organismic processes augment psychosocial desynchronization: the depressed person stops being in time, does not participate in joint decision-making, and at the level of concrete encounters a tendency towards stasis disrupts coordination with others in terms of bodily attunement (turn-taking, mutual expressivity and gestuality).

With respect to autism, Peter Hobson (e.g. 2009) similarly argues that it is misleading to reduce it to the impairment of a specific cognitive skill within a brain module, such as the capacity to 'read' other people's minds. In his view autism is best understood as primarily a disorder of one's affective engagement with others in faceto-face encounters, including the capacity directly to see feeling in facial expressions, to share feelings with others, and to understand what the other's emotions are directed toward. An impaired ability to read other minds, Hobson suggests, is the result rather than the cause of the autistic child's interpersonal difficulties. Disruptions in the capacity to participate in bodily social-affective 'forms of life' (to use Wittgenstein's term, as Hobson does) prevent the development of the capacity to share the other's experience and to take the other's perspective.

The embodied and situated nature of mental disorders is also apparent in accounts of the lived experience of mental illness. Existing accounts in phenomenological psychopathology underscore alterations in the experience of one's body and world, including other people. In the experience of depression, for example, one's own body comes to the foreground of awareness inducing a disproportionate absorption into one's bodily feelings and pain (Fuchs 2005, 2009). In social interactions, this self-absorption prevents depressives to enter into bodily and affective (gestural, expressive) resonance with others. Schizophrenia also comes with disorders of bodily self-awareness. Schizophrenics often have difficulties locating themselves ('Am I here or there? Am I here or behind?'; see Parnas and Sass 2001, p.106) and their bodily parts feel disconnected. As some put it, schizophrenia specifically involves a disorder of ipseity or pre-reflective bodily self-awareness, namely of the ordinarily tacit awareness we have of our body as ours and as the agent of our actions (e.g. Parnas and Sass 2001; Sass 2004). It is argued in particular that schizophrenia involves bodily hyper-reflexivity, namely an automatic 'popping into 
awareness' of bodily sensations that would ordinarily stay in the background. At the same time, this condition comes with several disorders in the experience of other people: the boundaries between oneself and others are experienced as blurred, and the generation and control of one's own actions and thoughts are often attributed to others; at the level of concrete interaction, schizophrenics appear to lack pre-reflective and pragmatic or commonsensical understanding of other's affectivity and intentionality (hence Stanghellini and Ballerini's 2004 term 'schizophrenic autism'). In addition, the physical world appears alien and strange, flat and disproportionally detailed; objects and utensils do not afford the actions they normally do, and aspects or events in the world lose their salience. As Sass (2004) puts it, schizophrenia involves an experience of 'unworlding'.

Now, one could remark that none of these considerations refute the claim that any mental illness really is a neurochemical impairment, and that disruptions in bodily activity, situatedness and experience are either causes or effects of such an impairment, but not events constitutive of the illness. Indeed most cognitive neuroscientists are ready to acknowledge that body and environment affect the brain, and vice-versa, while they still think of the mind as somehow primarily dependent on, and/or even located in, the brain.

From an enactive perspective however, to see the non-neural body and the environment as merely contingently related to one's mental life, including mental illness, is to misconstrue the relationship between the mind and the physical world. The brain does not sit in the organism as a central processing system, representing information about the world that comes to it through bodily sensory channels, and causing the body to act according to specific instructions. Rather the brain is physically entangled with the rest of the organism via a very complex network of continuous reciprocal exchanges of energy and matter (see Cosmelli and Thompson 2010 for a detailed account of the various dimensions of brain-body coupling). From a biological point of view, the brain is an organ able to perform its functions only when embedded in the context of an autonomous living being; living beings at the same time emerge from and are sustained throughout by the environment to which they are coupled. Thus the idea that one can isolate the nervous system from the network of causal interrelations in which it is so deeply embedded to designate it as the seat or source of mentality is a chimera. To construe mental illness as 'merely' a neural impairment is equally misleading, the result of the same neurocentric prejudice. 
Because of its emphasis on the embodied and situated nature of the mind, when it comes to treatment an enactive perspective calls for a pluralistic approach that does not exclude the use of drugs, but also favours 'alternative' therapies such as bodily and interactive practices. Various such practices already exist—see for example Gutstein's (2009) Relationship Development Intervention (RDI) approach to treating autism, which includes exercises of bodily coordination and turn-taking to restore affective resonance with others; music therapy, such as improvised musicmaking, is also used to engage autistic children in dialogical interactions and coordination with others (e.g. Wigram and Elefant 2009); and in Röhricht et al.'s (2009) bodywork treatment for chronic schizophrenia subjects are asked to engage in a variety of tasks involving their body, from dance movement therapy to NeoReichian body psychotherapy and sensory awareness. It follows from the preceding paragraph however that, from an enactive perspective, these practices are not mere indirect ways to act distally on the alleged primary source of mental illness, i.e. the brain; rather they act directly on concrete constitutive parts of the disorder. Irrespective of whether or not these practices end up affecting neural activity, they should be seen as directly manipulating the disorder itself.

\subsection{Cognitive-affective shifts in mental disorders}

Finally let us briefly consider the convergence between the enactive view that cognition is inherently affective, and current views in psychopathology. There is a close relationship between the enactive view that living systems are sense-making systems that enact their Umwelt, and the notion of existential feelings discussed by Ratcliffe (2008) and introduced earlier. The latter, as we saw, consist in feelings of how one 'finds oneself in the world'. They are thus world-oriented experiences, however at the same time they are bodily feelings - not in the sense that they take the body as an intentional object, but in the sense that they are bodily experiences of the world, experiences of the world-through-the-body. Likewise the enactive notion of sense-making implies that the world one finds oneself in (one's Umwelt) is always correlated to one's bodily structure and experience.

According to Ratcliffe (2008), disorders such as schizophrenia, depression, Capgras' syndrome, etc. involve radical shifts in existential feeling - as shown for example by changes in how one's own body is experienced, and correlatively by 
changes in how the world appears to the subject. From an enactive perspective, psychiatric disorders are to be understood as shifts in sense-making, resulting in an extra-ordinary and therefore often disconcerting Umwelt. Importantly, for both approaches these shifts are cognitive and affective at the same time. They are cognitive in the sense that they involve changes in perception, imagination, and understanding of others, which take different forms depending on the disorder in question. However these cognitive changes are not appropriately characterized merely in terms of changes in one's propositional beliefs. Rather they involve deeper changes in what strikes one as salient; in what demands attention and affords interaction, and what does not anymore; in the awareness of one's possibilities of sensorimotor and affective relations to the world. These changes thus also encompass, crucially, the sphere of personal salience and affectivity, which thus cannot really be disentangled from their cognitive dimension.

Both notions of sense-making and existential feelings cut across the widespread conceptual divide between feelings, body, and intentionality/cognition. This divide is deeply entrenched in the analytic tradition of philosophy of mind and emotion, in which feelings are typically characterized as 'mere feelings', that is, nonintentional conscious states dislocated from any meaningful action and interaction with the world. The same tradition typically sees bodily phenomena (behaviour, expression, physiological changes and bodily sensations) as mere effects of cognitive processes (such as judgments) that do not participate in the activity of making sense of the world. As we have seen, from an enactive perspective bodily processes are, rather, constitutive of the process of perceiving and interpreting the world, both experientially and subpersonally, and the distinction between cognition and affectivity is rejected accordingly. Existential feelings similarly cut across the distinction between cognition and affect, intentionality and bodily feelings. In existential feeling, the feeling body is constitutive of one's sense of reality; the latter is not provided by a disembodied faculty of cognition, but is given to the subject via the world-feeling body. To appeal to these notions to account for mental illness implies, then, acknowledging the complex holistic shift that this brings with it. Mental illness amounts neither only to disruptions of cognitive-propositional skills, nor only to alterations of affectivity and mood. Rather it involves a more radical and deeper cognitive-affective shift in how one makes sense of one's world including oneself in it. 


\section{Conclusion}

In sum then, there are various common threads between the enactive approach, and current trends and practices in psychopathology. These common threads depend mainly on the fact that both the enactive approach and psychopathology have 'phenomenological connections'; as such, they both value lived experience, emphasize the bodily and situated character of the mind, and the fact that what is constructed as salient depends constitutively on the organism's structure, interests and goals.

To be aware of these commonalities is important to generate further ideas and methods. We have seen for example that an enactive neurophenomenological approach could be explicitly adopted to explore whether and how experience and neurophysiological processes correlate in mental disorders; also, emphasizing the complexity of the mutual relations of brain, body and world, as enactivism does, can provide reasons within psychopathology as to why mental illness should not be reduced to neurochemical impairments, and as to why alternative forms of treatment such as bodily practices should be considered equivalent to drug-based therapy. These are only some initial ideas. Given the current thriving intellectual atmosphere surrounding both enactivism and psychopathology, I believe that more convergences are likely to be identified and developed into more precise research programs in the near future.

\section{Acknowledgements}

Thanks to Adam Zeman for his comments on an early draft of this paper, and to Richard Gipps for his thoughtful review and advice. This work has been funded by the European Research Council under the European Community's Seventh Framework Programme (FP7/2007-2013), ERC grant agreement nr. 240891.

\section{References}

Birbaumer, N., and Kimmell, H.D. (1979) (eds.). Biofeedback and Self-Regulation. Hillsdale, NJ: Lawrence Erlbaum. 
Brooks, R. (1991). Intelligence without representations. Artificial Intelligence, 47, 139-159.

Clark, A. (1997). Being There: Putting Mind, Brain and Body Together Again. Cambridge, MA: MIT Press.

Colombetti, G. (2007). Enactive appraisal. Phenomenology and the Cognitive Sciences, 6, 527-546.

Colombetti, G. (2010). Enaction, sense-making and emotion. In: J. Stewart, O. Gapenne, and E.A. Di Paolo (eds.). Enaction: Toward a New Paradigm for Cognitive Science. Cambridge, MA: MIT Press, pp. 145-164.

Colombetti, G. (in preparation). The Feeling Body. Cambridge MA: MIT Press.

Colombetti, G., and Thompson, E. (2008). The feeling body: towards an enactive approach to emotion. In: W.F. Overton, U. Müller, and J.L. Newman (eds.). Developmental Perspectives on Embodiment and Consciousness. Hillsdale, MJ: Lawrence Erlbaum, pp. 45-68.

Cosmelli. D., and Thompson, E. (2010). Embodiment or envatment? Reflections on the bodily bases of consciosness. In: J. Stewart, O. Gapenne, and E.A. Di Paolo (eds.). Enaction: Toward a New Paradigm for Cognitive Science. Cambridge, MA: MIT Press, pp. 361-386.

Cott, A., Pavloski, R., and Black, A. (1979). The role of sensorimotor rhythm feedback in the biofeedback treatment of epilepsy: a preliminary report. In: N. Birbaumer, and H.D. Kimmell (eds.). Biofeedback and Self-Regulation. Hillsdale, NJ: Lawrence Erlbaum, pp. 405- 412.

DeCharms, C.R. (2008). Applications of real time fMRI. Nature Neuroscience Reviews, 9, 720-729. 
De Jaegher, H., and Di Paolo, E.A. (2007). Participatory sense-making: an enactive approach to social cognition. Phenomenology and the Cognitive Sciences, 6, 485-507.

Dimberg, U., Thunberg, M., and Elmehed, K. (2000). Unconscious facial reactions to emotional facial expressions. Psychological Science, 11, 86-89.

Di Paolo, E.A. (2005). Autopoiesis, adaptivity, teleology, agency. Phenomenology and the Cognitive Sciences, 4, 429-452.

Drayson, Z. (2009). Embodied cognitive science and its implications for psychopathology. Philosophy, Psychiatry, \& Psychology, 16, 329-40.

Dreyfus, H.L. (1972). What Computers Can't Do: a Critique of Artificial Reason. New York: Harper and Row.

Frith, C.D., and Done, D.J. (1988). Towards a neuropsychology of schizophrenia. The British Journal of Psychiatry, 153, 437-443.

Fuchs, T. (2001). Melancholia as a desynchronization: towards a psychopathology of interpersonal time. Psychopathology, 34, 179-186.

Fuchs, T. (2005). Corporealized and disembodied minds: a phenomenological view of the body in melancholia and schizophrenia. Philosophy, Psychiatry \& Psychology, 12, 95-107.

Fuchs, T. (2009). Embodied cognitive neuropsychiatry and its consequences for psychiatry. Poiesis \& Praxis, 6, 219-233.

Gallagher, S. (2001). The practice of mind: theory, simulation or primary interaction? Journal of Consciousness Studies, 8, 83-108.

Gallagher, S. (2003). Phenomenology and experimental design: toward a phenomenologically enlightened experimental science. Journal of Consciousness Studies, 10, 85-99. 
Gallagher, S. (2005). How the Body Shapes the Mind. New York: Oxford University Press.

Gutstein, S.E. (2009). The RDI Book: Forging New Pathways for Autism, Asperger's and PDD with the Relationship Development Intervention Program. Perfect Paperback.

Hacking, I. (1995). Rewriting the Soul: Multiple Personality and the Sciences of Memory. Princeton, NJ: Princeton University Press.

Hacking, I. (1998). Mad Travellers: Reflections on the Reality of Transient Mental Illnesses. Cambridge, MA: Harvard University Press.

Hacking, I. (1999). The Social Construction of What? Cambridge, MA: Harvard University Press.

Heidegger, M. (1927/1962). Being and Time (trans. J. Macquarrie and E. Robinson). Oxford: Blackwell.

Hobson, R.P. (2009). Wittgenstein and the developmental psychopathology of autism. New Ideas in Psychology, 27, 243-257.

Hurley, S. (1998). Consciousness in Action. Cambridge, MA: Harvard University Press

Jaspers, K. (1913/1997). General Psychopathology (trans. J. Hönig and M.W. Hamilton). Baltimore and London: Johns Hopkins University Press.

Johnston, S.J., Boehm, S.G., Healy, D., Goebel, R., and Linden, D.E.J. (2010). Neurofeedback: a promising tool for the self-regulation of emotion networks. NeuroImage, 49, 1066-1072. 
Jonas, H. (1966/2001). The Phenomenon of Life: Toward a Philosophical Biology. Evanston, IL: Northwestern University Press.

Kelso, J.A.S. (1995). Dynamic Patterns. Cambridge, MA: MIT Press.

Le Van Quyen, M., Navarro, V., Martinerie, J., Baulac, M., and Varela, F.J. (2003). Toward a neurodynamical understanding of ictogenesis. Epilepsia, 44, 30-43.

Lutz, A., Lachaux, J-P., Martinerie, J., and Varela, F.J. (2002). Guiding the study of brain dynamics by using first-person data: synchrony patterns correlate with ongoing conscious states during a simple visual task. PNAS USA, 99, 1586-1591.

Matarić, M.J. (2002). Situated robotics. In L. Nadell (ed.). Encyclopedia of Cognitive Science. Nature Publishers Group, Macmillian Reference Ltd.

Maturana, H.R., and Varela, F.J. (1980). Autopoiesis and Cognition: The Realization of the Living. Boston Studies in the Philosophy of Science, vol. 42. Dordrecht: D. Reidel.

Merleau-Ponty, M. (1942/1963). The Structure of Behavior (trans. A. Fisher).

Pittsburgh, PA: Duquesne University Press.

Merleau-Ponty, M. (1945/1962). Phenomenology of Perception (trans. C. Smith). London: Routledge and Kegan Paul.

Mullen, P.E. (2007). A modest proposal for another phenomenological approach to psychopathology. Schizophrenia Bullettin, 33, 113-121.

Noë, A. (2004). Action in Perception. Cambridge, MA: MIT Press.

O’Regan, K.J., and Noë, A. (2001). A sensorimotor account of vision and visual consciousness. Behavioral and Brain Sciences, 24, 883-917. 
Parnas, J., and Sass, L.A. (2001). Self, solipsism, and schizophrenic delusions. Philosophy, Psychiatry \& Psychology, 8, 101-120.

Petitmengin, C., Navarro, V., and Baulac, M. (2006). Seizure anticipation: are neurophenomenological approaches able to detect preictal symptoms? Epilepsy and Behavior, 9, 298-306.

Petitmengin, C., Navarro, V., and Le Van Quyen, M. (2007). Anticipating seizure: pre-reflective experience at the center of neuro-phenomenology. Consciousness and Cognition, 16, 746-764.

Port, R.F., and van Gelder, T. (eds.)(1995). Mind as Motion. Cambridge, MA: MIT

Ratcliffe, M. (2008). Feelings of Being: Phenomenology, Psychiatry and the Sense of Reality. Oxford: Oxford University Press.

Ratcliffe, M. (2010). The phenomenology of mood and the meaning of life. In: P. Goldie (ed.). Oxford Handbook of Philosophy of Emotion. Oxford: Oxford University Press, pp. 349-372.

Rizzolatti, G., and Sinigaglia, G. (2006/2008). Mirrors in the Brain (trans. F. Anderson). Oxford: Oxford University Press.

Röhricht, F., Papadopoulos, N., Suzuki, I., and Priebe, S. (2009). Ego-pathology, body experience, and body psychotherapy in chronic schizophrenia. Psychology and Psychotherapy: Theory, Research and Practice, 82, 19-30.

Roy, J-M., Petitot, J., Pachoud, B., and Varela, F.J. (1999). Beyond the gap: an introduction to naturalizing phenomenology. In: J-M. Roy, J. Petitot, B. Pachoud, \& F.J. Varela (eds.). Naturalizing Phenomenology: Issues in Contemporary Phenomenology and Cognitive Science. Stanford: Stanford University Press, pp.1-80. 
Sass, L.A. (1992). Madness and Modernism: Insanity in the Light of Modern art, Literature, and Thought. Basic Books.

Sass, L.A. (2004). Affectivity in schizophrenia: a phenomenological view. Journal of Consciousness Studies, 11, 127-147.

Sass, L.A., Parnas J., and Zahavi, D. (2011). Phenomenological psychopathology and schizophrenia: contemporary approaches and misunderstandings. Philosophy, Psychiatry, \& Psychology, 18, 1-23.

Scherer, K. (2009). The dynamic architecture of emotion: evidence for the component process model. Cognition and Emotion, 23, 1307-51.

Segal, Z.S., Williams M.G., and Teasdale, J.D. (2001). Mindfulness-based Cognitive Therapy for Depression: a New Approach to Preventing Relapse. New York, London: Guilford.

Spiegelberg, H. (1972). Phenomenology in Psychology and Psychiatry: a Historical Introduction. Evanston: Northwestern University Press.

Stanghellini. G. (2004). Disembodied Spirits and Deanimated Bodies: the Psychopathology of Common Sense. Oxford: Oxford University Press.

Stanghellini, G., and Ballerini, M. (2004). Autism: disembodied existence. Philosophy, Psychiatry, \& Psychology, 11, 259-268.

Stern, D.N. (1985). The Interpersonal World of the Infant: a View from Psychoanalysis and Devlopmental Psychology. London: Karnac.

Stewart, J., Gapenne, O., and Di Paolo, E.A. (eds.) (2010). Enaction: a New Paradigm for Cognitive Science. Cambridge, MA: MIT Press.

Thelen, E., and Smith, L.B. (1994). A Dynamic Systems Approach to the Development of Cognition and Action. Cambridge, MA: MIT Press. 
Thelen, E., Schöner, G., Scheier, C., and Smith, L.B. (2001). The dynamics of embodiment: a field theory of infant perseverative reaching. Behavioral and Brain Sciences, 24, 1-86.

Thompson, E. (2007). Mind in Life: Biology, Phenomenology, and the Sciences of Mind. Cambridge MA: Harvard University Press.

Thompson, E., Lutz, A., and Cosmelli, D. (2005). Neurophenomenology: an introduction for neurophilosophy. In: A. Brook, \& K. Akins (eds.). Cognition and the Brain: the Philosophy and Neuroscience Movement. New York and Cambridge: Cambridge University Press, pp. 40-97.

Trevarthen, C. (1979). Communication and cooperation in early infancy: a description of primary intersubjectivity. In: M. Bullowa (ed.). Before Speech: The Beginning of Interpersonal Communication. Cambridge: Cambridge University Press, pp. 321-347.

Varela, F.J. (1996). Neurophenomenology: a methodological remedy for the hard problem. Journal of Consciousness Studies, 3, 330-350.

Varela, F.J., Thompson, E., and Rosch, E. (1991). The Embodied Mind: Cognitive Science and Human Experience. Cambridge, MA: MIT Press.

Von Uexküll (1921). Umwelt und Innenwelt der Tiere. Berlin: Springer.

Weber, A., and Varela, F.J. (2002). Life after Kant: natural purposes and the autopoietic foundations of biological individuality. Phenomenology and the Cognitive Sciences, 1, 97-125.

Wheeler, M. (2005). Reconstructing the Cognitive World: The Next Step. Cambridge, MA: MIT Press.

Wigram, T., and Elefant, C. (2009). Therapeutic dialogues in music: nurturing musicality of communication in children with autistic spectrum disorder and Rett 
syndrome. In: S. Malloch, and C. Trevarthen (eds.). Communicative Musicality:

Exploring the Basis of Human Companionship. Oxford: Oxford University Press, pp. 423-445.

Zahavi, D. (2007). Expression and empathy. In: D.D. Hutto, and M. Ratcliffe (eds.).

Folk-Psychology Reassessed. Dordrecht: Springer, pp. 25-40. 